The University of Southern Mississippi

The Aquila Digital Community

Master's Theses

Spring 5-2017

\title{
Overparenting and Emerging Adults' Mental Health: The Mediating Role of Emotional Distress Tolerance
}

Christopher Michael Perez

University of Southern Mississippi

Follow this and additional works at: https://aquila.usm.edu/masters_theses

Part of the Clinical Psychology Commons, Counseling Psychology Commons, Counselor Education Commons, Family, Life Course, and Society Commons, and the Multicultural Psychology Commons

\section{Recommended Citation}

Perez, Christopher Michael, "Overparenting and Emerging Adults' Mental Health: The Mediating Role of Emotional Distress Tolerance" (2017). Master's Theses. 271.

https://aquila.usm.edu/masters_theses/271

This Masters Thesis is brought to you for free and open access by The Aquila Digital Community. It has been accepted for inclusion in Master's Theses by an authorized administrator of The Aquila Digital Community. For more information, please contact Joshua.Cromwell@usm.edu. 
OVERPARENTING AND EMERGING ADULTS' MENTAL HEALTH: THE

MEDIATING ROLE OF EMOTIONAL DISTRESS TOLERANCE

by

Christopher Michael Perez

\begin{abstract}
A Thesis
Submitted to the Graduate School

and the Department of Psychology

at The University of Southern Mississippi

in Partial Fulfillment of the Requirements

for the Degree of Master of Arts
\end{abstract}

Approved:

Dr. Bonnie C. Nicholson, Committee Chair

Associate Professor, Psychology

Dr. Eric R. Dahlen, Committee Member

Associate Professor, Psychology

Dr. Melanie E. Leuty, Committee Member

Associate Professor, Psychology

Dr. Karen S. Coats

Dean of the Graduate School

May 2017 


\section{COPYRIGHT BY}

Christopher Michael Perez

2017

Published by the Graduate School

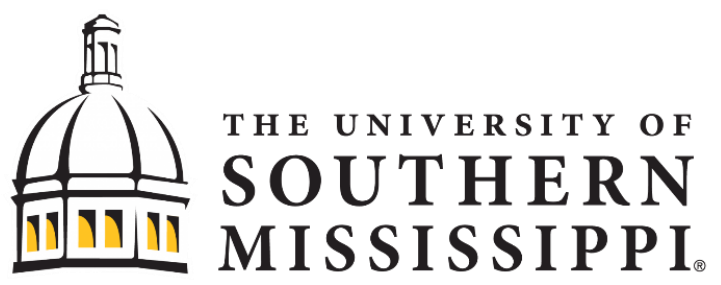




\begin{abstract}
OVERPARENTING AND EMERGING ADULTS' MENTAL HEALTH: THE MEDIATING ROLE OF EMOTIONAL DISTRESS TOLERANCE

by Christopher Michael Perez
\end{abstract}

May 2017

Overparenting is a type of parental control that features intense parental involvement, which is negatively associated with the development of age-appropriate autonomous behavior in children and emerging adults. To this point, overparenting has been linked to poor mental health in young children (Bayer, Sanson, \& Hemphill, 2006; Gar \& Hudson, 2008), as well as in emerging adults (LeMoyne \& Buchanan, 2011; Segrin, Woszidlo, Givertz, \& Montgomery, 2013). The emerging adult population has continued to be one of interest across recent studies concerning mental health, given the unique emotional and behavioral changes that arise during this stage of development. Emotional distress tolerance (DT), defined as the ability to withstand negative emotional states (Anestis et al., 2012; Simons \& Gaher, 2005), has not yet been established as a construct in relation to overparenting. The present study examined the direct role of overparenting in relation to mental health symptoms in emerging adults and explored emotional DT as a mediator of this relationship. College student participants $(\mathrm{N}=360)$ completed a demographic questionnaire, as well as questionnaires regarding perceived parental control, depression, stress, anxiety, and emotional distress tolerance. As hypothesized, the results indicated that emotional DT was negatively correlated with levels of perceived overparenting. Furthermore, it was found that emotional DT mediated 
the relationship between overparenting and emotional distress in emerging adulthood, when accounting for race and perceived parental involvement as covariates. 


\section{ACKNOWLEDGMENTS}

Special thanks goes to my committee chair and advisor, Dr. Bonnie Nicholson, as well as my other committee members, Dr. Eric Dahlen and Dr. Melanie Leuty, for the time, effort, and dedication they have provided towards my continuing education and career fulfillment. 


\section{DEDICATION}

My warmest expressions of love, care, and gratitude are extended to my parents, Teresita and Michael Perez, for their constant provision of understanding, support, and prayer throughout my time as a graduate student. Further thanks are extended to my sisters, Elizabeth Perez, Mary Sarah Perez, and Lindsey Mann, as well as my partner, Briana Olivia Taylor, for expressing their love, kindness, and pride in my work.

A truly special dedication goes to my grandfather, the late Dr. Vernon J. Perez, for dedicating his life to our family, as well as advancing the field of psychology, during his lifetime. My ambition and inspiration would not exist if it were not for the path he left to guide me. 


\section{TABLE OF CONTENTS}

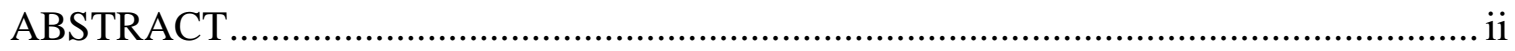

ACKNOWLEDGMENTS ............................................................................ iv

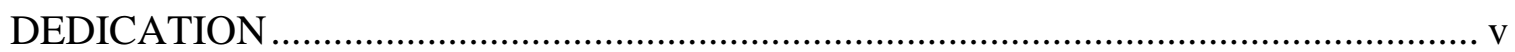

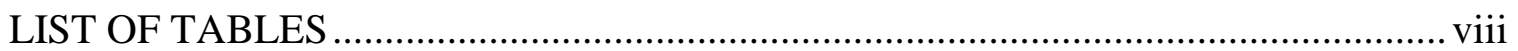

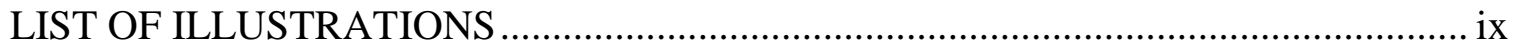

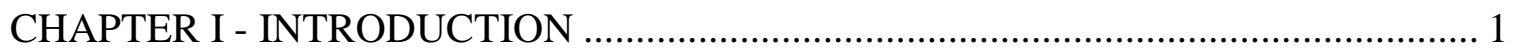

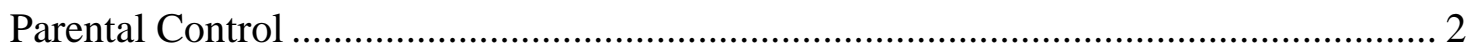

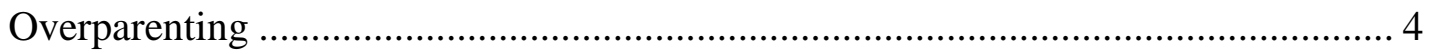

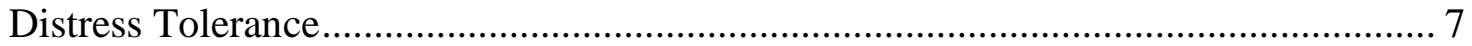

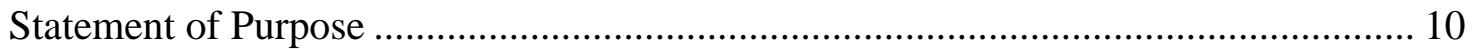

Research Questions and Hypotheses ............................................................. 11

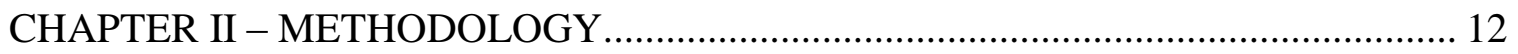

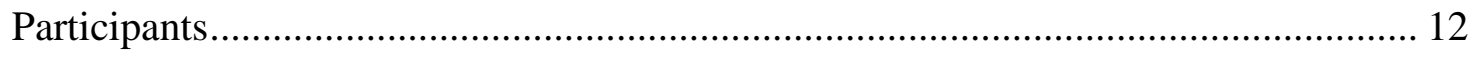

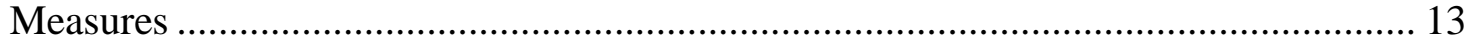

Demographic Questionnaire .................................................................. 13

Helicopter Parenting Instrument (HPI) ......................................................... 14

Distress Tolerance Scale ..................................................................................... 14

Depression, Anxiety, Stress Scales - 21 (DASS-21)........................................... 15

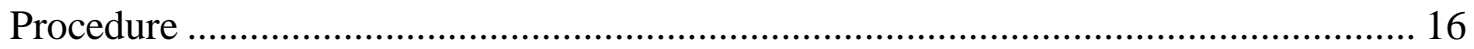




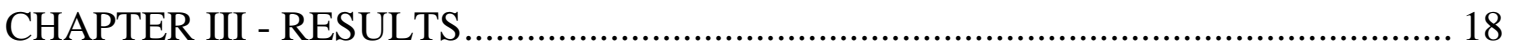

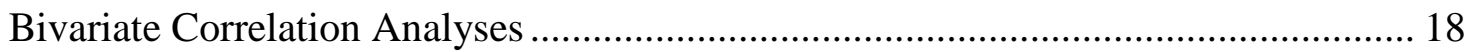

Initial Second-Order Confirmatory Factor Analysis: DASS-21 …………………..... 19

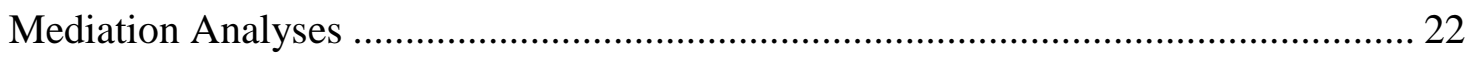

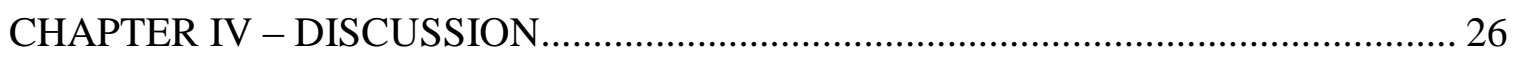

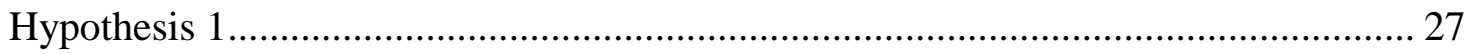

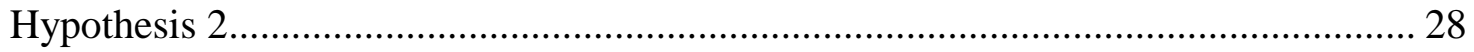

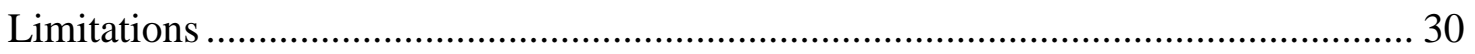

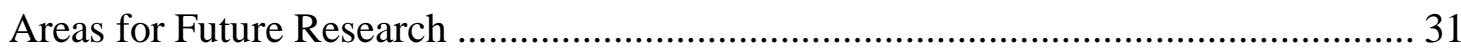

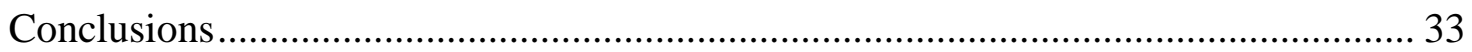

APPENDIX A - DEMOGRAPHIC QUESTIONNAIRE …………………………….... 34

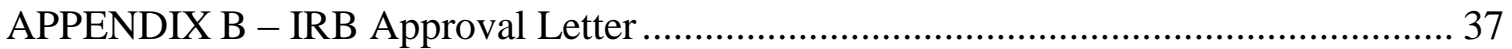

APPENDIX C ELECTRONIC INFORMED CONSENT …………………................. 38

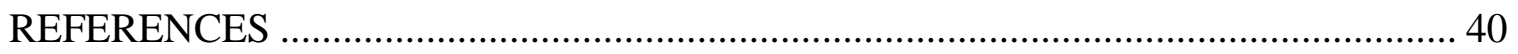




\section{LIST OF TABLES}

Table 1 Reliability Coefficients, Means, Standard Deviations, and Correlations for Study

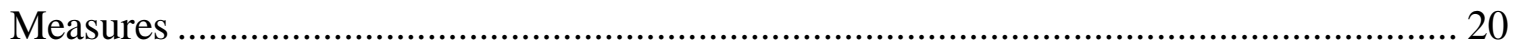




\section{LIST OF ILLUSTRATIONS}

Figure 1. Confirmatory Factor Analysis using Depression, Stress, Anxiety Scales - 2121

Figure 2. Mediation Analysis with Observed Variable of Emotional Distress ............... 23

Figure 3. Mediation Analysis Using the Depression Subscale of the Depression, Anxiety,

Stress Scales - 21 as a Dependent Variable ............................................................ 24

Figure 4. Mediation Analysis Using the Stress Subscale of the Depression, Anxiety,

Stress Scales - 21 as a Dependent Variable …........................................................ 25

Figure 5. Mediation Analysis Using the Anxiety Subscale of the Depression, Anxiety,

Stress Scales - 21 as a Dependent Variable .............................................................. 25 


\section{CHAPTER I - INTRODUCTION}

Overparenting is a form of over-involved parenting in which parents' intrusive control restricts their children's capability to develop age-appropriate autonomous behaviors (Segrin, Woszidlo, Givertz, Bauer \& Murphy, 2012). The majority of the literature to this point has found that overparenting is positively correlated with young children's tendencies to be anxious, withdrawn, depressive, and insecure (Bayer et al., 2006; Gar \& Hudson, 2008; Schiffrin et al., 2014). Recently, studies have examined overparenting as a predictor of negative mental health symptoms in emerging adulthood (Schiffrin et al., 2014), which has been characterized as the time from the end of adolescence to the young-adult responsibilities of a stable job, marriage, and parenthood (Arnett, 2007). However, the mechanisms at work in this relationship have not yet been investigated.

Emotional distress tolerance (DT) has been characterized as an individual's capacity to tolerate negative psychological and emotional states (Hawkins, Macatee, Guthrie, \& Cougle, 2013). For example, lower levels of DT have been associated with emerging adults' inability to appropriately express anger when anxiety and depression were accounted for (Hawkins et al., 2013). Daughters and colleagues (2014) found that the social expressions of emerging adults' emotions and emotion regulation are environmentally influenced, particularly in the family context. Considering this, it has been suggested that parental behaviors may contribute to lower levels of DT. To this point, DT has been found to mediate the relationships between impulsivity and alcohol use coping motives (i.e., drinking to cope with emotions) (Marshall-Berenz, Vujanovic, \& MacPherson, 2011), posttraumatic stress and marijuana use coping motives (Potter, 
Vujanovic, Marshall-Berenz, Bernstein, \& Bonn-Miller, 2011), as well as anxiety sensitivity and bulimia (Anestis, Selby, Fink, \& Joiner, 2007). However, studies have yet to examine the mediating role of DT within the context of parental control and mental health correlates. Both overparenting and emotional DT have been correlated with stress, anxiety, and depression, but the mediating role of emotional DT has not been examined in this context. The present study hypothesized that emotional DT may mediate the relationship between overparenting and negative mental health correlates in emerging adults.

\section{Parental Control}

Parental behavioral control has been defined as the rules and restrictions implemented by parents toward their children (e.g., monitoring activities) that may involve the induction of guilt, withdrawal of love, and assertion of authority ( $\mathrm{Li}, \mathrm{Li}, \&$ Newman, 2013). Behavioral control has also been characterized by parents' attempts to regulate children's behaviors (e.g., schoolwork, chores, communication) within everyday environments (Padilla-Walker \& Nelson, 2012). Schaefer (1965) found higher levels of behavioral parental control to be associated with significantly lower levels of parental warmth and responsiveness. These parental control types are found to be predictive of negative mental health symptoms in both childhood and emerging adulthood (LeMoyne \& Buchanan, 2011). Segrin and colleagues (2012) found high levels of behavioral control, such as advice giving, protectiveness, and preoccupation, had a negative relationship with reports of emerging adults' level of happiness. This study indicated that high parental involvement also was predictive of lower levels of autonomous functioning in emerging adults (Segrin et al., 2012). 
By contrast, parental psychological control has been typified by parents' attempts to coerce their children into thinking, feeling, or behaving in a specific way through the withdrawal of affection, guilt, intrusiveness, and invalidation (Bebes, Samarova, Shilo, \& Diamond, 2013). Additionally, parental psychological control has been characterized as parents' attempts to express disappointment, invoke guilt, and dismiss children's love (Hauser Kunz \& Grych, 2013). Schaefer (1965) further found parental psychological control to be correlated with decreased levels of warmth and responsiveness, similar to that of parental behavioral control. Recent studies involving psychological parental control have found associations with negative correlates such as communication deficiencies and greater levels of depression and anxiety in emerging adults (Odenweller, Booth-Butterfield, \& Weber, 2014). High levels of parental psychological control have been positively correlated with both externalizing (e.g., recreational pain killer abuse) and internalizing (e.g., distancing) behaviors in emerging adults (LeMoyne \& Buchanan, 2011). High levels of psychological control have also been found to be predictive of poor emotion regulation in emerging adulthood (Manzeske \& Stright, 2009). In sum, excessive behavioral and psychological control seem to be associated with negative mental health symptoms in emerging adulthood such as depression, anxiety, and stress. Recently however, a third type of control pattern, popularized as helicopter parenting (i.e., overparenting) by the media, has received some empirical attention. This third type of parental control may have unique correlations with the development of autonomous behaviors, as well as mental health, in emerging adults. 


\section{Overparenting}

Overparenting is characterized by intensive "hands on" approaches to parental control (Schiffrin et al., 2013). Overparenting is a term also referred to as helicopter parenting, named as such due to parents' tendencies to excessively "hover" over their emerging adult children. This parenting style has been challenging to investigate, considering the different ways it has been labeled (e.g., overparenting, helicopter parenting, intrusive parenting) by various researchers, making cross-study comparisons difficult. Until recently, overparenting was considered a style of parental control that shared traits with both psychological and behavioral control. However, Padilla-Walker and Nelson (2012) determined that a three-factor solution (i.e., behavioral control, psychological control, helicopter parenting) provided the best statistical solution offering some support for overparenting as a construct distinct from the other types of parental control, through using measures with items created to assess each of these constructs. This three-factor model was consistent across various respondents (i.e., Child-report mother, Child-report father, Mother-report, Father-report). Specifically, Padilla-Walker and Nelson (2012) found that psychological and behavioral control do not share the same levels of high parental involvement that overparenting involves. Additionally, PadillaWalker and Nelson (2012) noted that, in contrast to psychological and behavioral control, individuals who overparent provide excessive warmth and engage in restricted ageappropriate autonomy development. Furthermore, the authors explained that the distinctions are better highlighted through acknowledging that overparenting does not intentionally target the emotional or psychological autonomy of the child, although individuals who overparent do display restrictive parenting behaviors that inadvertently 
decrease the development of age-appropriate autonomous behaviors such as negotiating (Segrin et al., 2012), resolving interpersonal conflict, decision-making, finance management, and academic-related skills (Padilla-Walker \& Nelson, 2012).

Researchers have suggested that overparenting has an impact on emerging adulthood across "system-wide" environments (Odenweller et al., 2014), suggesting that overparenting may affect emerging adults in a variety of settings (e.g., academic, family, workplace). Odenweller et al. (2014) conducted a study regarding overparenting at a large Mid-Atlantic university in a sample of 268 college students, which found that sixty to seventy percent of student participants reported experiencing overparenting in their respective households. Locke, Campbell, and Kavenaugh (2012) found that the majority of parent-participants who endorsed behaviors related to overparenting reported being highly educated, earning dual-incomes, and focused on their emerging adult children's academic achievement. Additionally, Odenweller et al. (2014) found that while parents seem to communicate consistently with their children, it may be considered excessive in some cases.

Overparenting behaviors (e.g., intrusion, autonomy restriction) appear to be correlated with mental health concerns in emerging adulthood (LeMoyne \& Buchanan, 2011; Padilla-Walker \& Nelson, 2012; Schiffrin et al., 2014; Segrin, Givertz, Swaitowski, \& Montgomery, 2015). Specifically, associations have been found between overparenting and ineffective coping skills (i.e., internalizing, distancing), and narcissism, anxiety, and stress in emerging adulthood (Segrin et al., 2013). Overparenting has also been associated with psychological distress, which may be related to emerging adult children's levels of depression, anxiety, and perceived stress (LeMoyne \& 
Buchanan, 2011; Schiffrin et al., 2014; Segrin et al., 2013). Particularly, the overprotectiveness related to overparenting has been connected with reports of greater perceived stress in emerging adults (Sideridis \& Kafetsios, 2008). Overparenting has also been linked to a higher risk of negative mental and physical health concerns such as substance abuse in emerging adults (Needham \& Austin, 2010). Odenweller and colleagues (2014) found that emerging adults who experienced overparenting reported greater depressive symptoms, abused painkillers more frequently, and were prescribed to antidepressant medication more often than emerging adults who did not report perceived overparenting behaviors. Considering these findings, the current study intended to examine emotional DT as a potential mechanism through which overparenting may work to facilitate these symptoms.

To this point, preliminary evidence suggests overparenting may predict emotional distress in emerging adults. However, the mechanisms by which this happens are unclear. Distress tolerance has been shown to be predictive of distress in this population (Kraemer, Luberto, \& McLeish, 2012; Potter et al., 2010), and may have links to parental behaviors. Thus, it is plausible that emotional DT could be the mechanism through which overparenting is connected to negative mental health symptoms in emerging adulthood. Considering these findings, it was proposed that overparenting would be negatively associated with emerging adults' ability to tolerate emotional distress, which in turn may be predictive of negative mental health concerns in this population. Thus, the intention of the present study was to examine the mediating role of emotional DT between perceived overparenting and mental health correlates (i.e., stress, anxiety, depression) in emerging adults. 


\section{Distress Tolerance}

Distress tolerance (DT) was originally defined as an individual's ability to maintain goal-directed behavior while enduring physical or psychological distress (Daughters et al., 2014). Broadly, mental health professionals have understood DT to be comprised of the capability to tolerate negative internal states such as emotion, ambiguity, uncertainty, frustration, and physical discomfort (Leyro, Zvolensky, \& Bernstein, 2010). Until recently, studies regarding DT have focused predominantly on behavior (e.g., risky behavior, smoking, trait aggression) and behavioral measures (Lejuez, Banducci, \& Long, 2013). More recently, researchers have examined emotional and psychological reactions to DT separately. In emerging adulthood, emotional DT has been associated with symptoms of anxiety (Keough, Riccardi, Timpano, Mitchell, \& Schmidt, 2010), depression (Ellis, Fischer, \& Beevers, 2010), and worry (Huang, Szabo, \& Han, 2009). Related to this, Ellis, Vanderlind, and Beevers (2013) found a negative relationship between emotional DT and self-reported anger in a sample of emerging adults. Studies have also found that individuals with low emotional DT tend to exhibit lower impulsivity, associated with alcohol (Marshall-Berenz et al., 2011) and marijuana (Potter et al., 2011) coping motives. Ali, Beck, and Daughters (2013) found that emerging adults with low emotional DT also tended to engage in substance abuse (i.e., alcohol). In a sample of college students, Gaher, Hofman, Simons, and Hunsaker (2013) found trauma exposure to be predictive of low emotional DT, which in turn was indirectly related to impulsivity, negative urgency, and alexithymia.

Currently, there is a limited amount of literature investigating the associations between parenting in general and/or overparenting in particular, and emotional DT in 
emerging adulthood. Eisenberg, Cumberland, and Spinrad (1998) found that children who receive encouragement from parents respond to distress more effectively than children who receive negative reactions related to their distress. Morris, Silk, Steinberg, Myers, and Robinson (2007) suggested that child and adolescent emotional DT are regulated through the observation of parents and family, emotion-relevant parenting practices, and the emotional climate of respective families. Gender has also been found to moderate the relationship between both maternal and adolescent emotional DT, with findings concluding that maternal emotional DT impacts only adolescent daughters' emotional DT significantly (Daughters et al., 2014). High levels of parental control have also been found to predict emotion dysregulation in adolescents and emerging adults (Manzeske \& Stright, 2009; McDowell, Kim, O’Neil, \& Parke, 2002; Moilanen, 2007; Strayer \& Roberts, 2004). Specifically, Manzeske and Stright (2009) noted that when parental control is not adjusted for the appropriate developmental levels expected of emerging adults, autonomy does not develop, and this may be related to problems with emotion regulation. Thus, Manzeske and Stright (2009) proposed that parental psychological control was predictive of negative emotional arousal, which in turn may predict emerging adults' ability to tolerate negative emotions and distress. In other words, this suggests that parents' efforts to control their offspring's emotions may be associated with emotional DT. Tucker, Holt, and Wiesen-Martin (2013) found that levels of parental warmth and communication in those who overparent mediated the relationship between interparental conflict and depression in female emerging adults. Interestingly, Cusimano and Riggs (2013) found that interparental conflict encountered by individuals in childhood is significantly related to psychological functioning and levels of distress in 
college students. Rhoades and Wood (2014) examined college students' positive and negative emotions regarding family mediating the association between family conflict and social adjustment, finding that college-students' self-reports of emotional distress were a key element in explaining the relationship between family conflict and social adjustment. Thus, it seems reasonable to posit that parents' behaviors, perceived as undesirable or negative by emerging adult children, may influence the ways in which said children tolerate, adapt, and behave in the presence of negative emotional experiences.

Researchers have examined individual characteristics (e.g., behavior, personality) and contextual factors (e.g., family) related to emotional DT in childhood (Ehrlich, Cassidy, Gorka, Lejuez, \& Daughters, 2013). In relation to overparenting, Hudson and Dodd (2012) found that mothers' intrusive parenting behaviors were important risk factors for the early onset of clinical anxiety in middle-childhood. Recent studies have found emotional DT to be a major contributing variable to mental health correlates (e.g., anxiety, depression) in college students (Kaiser, Milich, Lynam, \& Charnigo, 2012). Researchers have recognized emotional DT as a potential predictor of changes in both psychopathology and behavioral health issues in emerging adults (Lejuez et al., 2013). Regarding this, Zvolensky and Hogan (2013) proposed that emotional DT contributes to the development and maintenance of phenotypes related to psychopathology and also as a key component of therapeutic change in psychological health. Zvolensky and Hogan (2013) also provided empirical evidence and theoretical approaches highlighting emotional DT as a key construct linked to risk and resiliency concerning the development of psychopathology. Hence, it is plausible that the extent to which parents engage in overparenting behaviors would be negatively correlated with their emerging adult 
children's emotional DT, which may be subsequently associated with emotional distress in emerging adulthood.

\section{Statement of Purpose}

Overparenting has been negatively associated with age-appropriate autonomous behavior in emerging adults, and positively correlated with stress, anxiety, and depression in emerging adulthood (LeMoyne \& Buchanan, 2011; Schiffrin et al., 2014; Segrin et al., 2013). The mechanisms by which overparenting may contribute to these symptoms are unclear. Emotional DT has been identified as a mediator in adult populations between anxiety sensitivity and bulimia (Anestis et al., 2007), Posttraumatic Stress Disorder (PTSD), and marijuana coping motives (Potter et al., 2011), as well as impulsivity and alcohol coping motives, and may be influenced by parenting behaviors (Manzeske \& Stright, 2009). The intrusive parental behaviors associated with overparenting are negatively associated with age-appropriate autonomous behaviors in emerging adulthood and greater reports of learned helplessness and dependency (Padilla-Walker \& Nelson, 2012). Previous research has found that emerging adults' dependence on their parents has also been associated with negative mental health symptoms such as anxiety, and depression (Soenens, Vansteenkiste, \& Luyten, 2010).

To this point, the significant findings within studies examining overparenting and mental health have typically been conducted in majority White/non-Hispanic, female samples (Lemoyne \& Buchanan, 2011; Locke, Kavanaugh, \& Campbell, 2016; PadillaWalker \& Nelson, 2012; Segrin et al., 2012; Segrin et al., 2013). Studies have not necessarily accounted for perceptions of parental involvement to account for variance above and beyond that contributed by measures of overparenting. Additionally, studies 
involving overparenting and mental health have yet to account for living situation(s) as a potential covariate. Considering this, it was hypothesized that overparenting would be negatively associated with emotional DT in emerging adulthood. Consequently, it was expected that emotional DT would be associated with stress, anxiety, and depression. To this point, the literature surrounding overparenting has not accounted for the indirect effects of emotional DT between overparenting and mental health symptoms in emerging adulthood. Given that overparenting has previously been associated with psychological and emotional distress, the current study aimed to determine whether emotional DT would partially mediate the relationship between overparenting and emotional distress (i.e., stress, anxiety, depression) in emerging adulthood while considering race, gender, perceived parental involvement, and participants' current living situation as covariates.

\section{Research Questions and Hypotheses}

Question 1: Is overparenting correlated with levels of emotional DT in emerging adulthood?

Hypothesis 1: It was hypothesized that overparenting would be negatively correlated with emotional DT in emerging adulthood.

Question 2: Does emotional DT partially mediate the relationship between overparenting and emotional distress (i.e., stress, anxiety, depression), as well as stress, anxiety, and depression independently, in emerging adulthood?

Hypothesis 2: It was hypothesized that emotional DT would partially mediate the relationship between overparenting and emotional distress (i.e., stress, anxiety, depression), as well as stress, anxiety, and depression independently, in emerging adulthood. 


\section{CHAPTER II - METHODOLOGY \\ Participants}

A total of 467 participants took part in the current study. Participants included undergraduate psychology students at a mid-sized university in the southeastern United States, who completed the questionnaires for class credit. After initial examination of the data, 59 participants were removed for failing validity checks. Specifically, 29 participants were removed for incorrectly answering a directed response item (i.e., Please answer "often" for this item). Thirty participants were excluded from the analyses after failing validity checks that indicated insufficient effort responding through analyzing the amount of time spent (i.e., $<10$ minutes) to complete the study. The estimated time of completion for the study was determined by averaging the completion time of recruited volunteers' questionnaires. The remaining 48 participants did not meet the required ages (18-25) for participation within the study, and were therefore removed from the analyses. Thus, a total of 360 valid participant responses were included in the final analyses.

Participants included 59 male (16.4\%) and 301 female (83.6\%) emerging adult college students, ranging 18 to 25 years of age $(M=19.93 ; S D=1.64)$. With regard to participants' racial/ethnic identification, 226 identified themselves as White/non-Hispanic (62.8\%), 114 as Black/African-American (31.7\%), eight as Asian-American (2.2\%), one as Native American (.3\%), and 11 as "Other" (3.1\%). Additionally, 145 participants identified as freshman (40.3\%), 81 sophomores (22.5\%), 71 juniors (19.7\%), 62 seniors $(17.2 \%)$, and 1 "Other" (.3\%). Related to identifying primary caregivers, 249 respondents identified their mother (69.2\%), 74 identified a father $(20.6 \%)$, four identified grandfather or other male family member (1.1\%), 14 identified grandmother or other female family 
member $(3.9 \%)$, one identified stepmother (.3\%), one identified stepfather $(.3 \%)$, and 17 identified "Other" (4.7\%). Lastly, 159 participants reported living on campus with roommates (44.2\%), 101 off-campus without parent or primary caregiver (with roommate) (28.1\%), 39 on-campus without roommates (10.8\%), 33 off-campus with parent or primary caregiver $(9.2 \%), 27$ off-campus without parent or primary caregiver without roommate $(7.5 \%)$, and one "other" $(.3 \%)$.

Measures

\section{Demographic Questionnaire}

A demographic questionnaire was utilized to collect information regarding participants' age, gender, college status, race, ethnicity, estimated family income, and “primary caregiver” (see Appendix A). Participants' primary caregiver was determined by stating, "This should be the parent or 'primary caregiver' that you consider to currently provide the most support in your life. Please indicate which option below best describes this primary caregiver." Choices for primary caregiver included "Mother," "Stepmother," "Father," "Stepfather," "Grandfather or other male family member (e.g., uncle)," "Grandmother or other female family member (e.g., aunt)," and "Other (please describe." One item was included within the current study to determine whether overparenting was associated with emerging adults' perceptions of parents' current involvement in their lives. Participants were asked, "On a scale from 1-10 (1= Not involved at all and $10=$ Very involved), how involved do you believe your parent or "primary caregiver" is in your life, currently?" Participants were also asked to rank their current levels of satisfaction $(1=$ Completely unsatisfied and $10=$ Completely satisfied $)$ within the parent-child relationship in order to determine whether a significant 
relationship existed between reports of perceived over parenting and parent-child relationship satisfaction.

\section{Helicopter Parenting Instrument (HPI)}

Overparenting was examined using the Helicopter Parenting Instrument (HPI;

Odenweller et al., 2014), which is a 14-item scale that measures emerging adults' reports of developmentally inappropriate overparenting behaviors. Items are assessed using a 7point Likert scale $(1=$ Very strongly disagree and $7=$ Very strongly agree $)$, with higher scores indicating greater perceived parental involvement. Total scores are found by summing each item score. Items include phrases such as, "My parent tries to make all of my major decisions," and "My parent overreacts when I encounter a negative experience." The HPI displayed an overall alpha of .76 in a college student sample (Odenweller et al., 2014).

\section{Distress Tolerance Scale}

Emotional DT was assessed using the Distress Tolerance Scale (DTS; Simons \& Gaher, 2005). The 14-item DTS measures perceived tolerance of emotional distress, participants' appraisal of distress, attention gained from negative emotions, and regulatory efforts towards alleviating distress. Items are rated using a five-point Likert scale (1= Strongly Agree and 5 = Strongly Disagree) with higher scores indicating higher levels of distress tolerance. Items include, "I can't handle feeling distressed or upset" and "I'll do anything to avoid feeling distressed or upset." The DTS consists of four subscales (i.e., ability to tolerate emotional distress, subjective appraisal of distress, attention absorbed by negative emotions, and regulation). Total scores can be found by summing subscale scores and then finding their average. Participants' overall scores were used as 
the mediating variable (i.e., distress tolerance). The DTS has displayed good test-retest reliability between reports of men and women over a six-month period $(r=.61)$ (Simons \& Gaher, 2005). The DTS subscales for tolerance, appraisal, absorption, and regulation, derived alpha coefficients of $.85, .82, .85$, and .72 , respectively, while an average score alpha of .89 was derived within the same sample (Simons \& Gaher, 2005). A study conducted by Leyro, Bernstein, Vujanovic, McLeish, and Zvolensky (2011) found internal consistency for the DTS with a total score alpha of .91 and subscale alphas ranging from $.66-.85$. Only the total score was used in the current study. Depression, Anxiety, Stress Scales - 21 (DASS-21)

The Depression Anxiety Stress Scales - 21 (DASS-21; Lovibond \& Lovibond, 1995) was administered to assess participants' levels of depression, anxiety, and stress. Participants reported the severity of symptoms experienced of the course of the previous week. DASS-21 items are rated on a 4-point Likert scale $(0=$ Did not apply to me at all and $3=$ Applied to me very much, or most of the time). Subscale scores are found by calculating the total score of seven individual items, with subscale scores ranging from 0 to 21 . Higher scores entail greater endorsement of that specific symptom set. Items include "I found myself getting agitated" for stress, "I felt that life was meaningless" for depression, and "I was aware of the action of my heart in the absence of physical exertion" for anxiety. Norms were derived from a study conducted by Osman and colleagues (2012) administered the DASS-21 to a sample of college student participants and found sufficient internal consistency, as subscale alpha coefficients ranged from .81 to .88. Supportive concurrent validity evidence was found, given high correlations with scores on the Beck Depression Inventory-II (BDI-II; Beck, Steer, \& Brown, 1996), the 
Beck Anxiety Inventory (BAI; Beck \& Steer, 1990), and the Perceived Stress Scale (PSS; Cohen, Kamarck, \& Mermelstein, 1983). A total score for the DASS-21 was used within the present study. To this point, limited studies have provided evidence supporting the combination of DASS-21 subscales to use as an observed variable of emotional distress. The results of a study conducted by Winner (2015) found factor loadings between a second-order factor of "emotional distress" and first-order factors of depression, anxiety, and stress to be $.89, .94$, and .93 , respectively. An additional Confirmatory Factor Analysis was conducted on data from the current study to provide additional support for using the total score. These analyses are reported in the results section.

\section{Procedure}

Following approval of this research by The University of Southern Mississippi's Institutional Review Board (see Appendix B), participants were recruited through the Department of Psychology's research participation program (http://usm.sonasystems.com/). Participants completed an informed consent form, along with the additional questionnaires through Qualtrics, a secure online survey system. Upon providing informed consent, participants completed a demographic questionnaire, followed by randomly ordered measures of parental control, emotional DT, and emotional distress (i.e., stress, anxiety, depression). The approximated time of completion for this study was 20-30 minutes.

Careless responding was checked through inclusion of two directed response items within the questionnaires (e.g., Answer "not at all" to this question). Participants who answered incorrectly to either of the directed response items were removed from analyses after completing the questionnaires. Similarly, the amount of time spent on each 
questionnaire acted as a validity check (Huang, Curran, Keeney, Poposki, \& DeShon, 2012). Researchers assisting in this study read through the questionnaires at an average pace while answering item content and determined that the minimum amount of time necessary in order to complete the study while reading the instructions for each questionnaire and responding thoughtfully to each question was 10 minutes. Therefore, participants who completed the study in less than 10 minutes were removed from the study in order to promote data integrity, as it was assumed they were not adequately attending to all item content. 


\section{CHAPTER III - RESULTS}

For the current study, participants who failed quality assurance checks or did not complete at least $75 \%$ of the items were removed from the study $(\mathrm{N}=107)$. Missing values were replaced using linear trend at point imputation, while outliers were handled using truncation. To ensure statistical normality, pseudo-z scores were derived, which did not warrant any concern (Field, 2013). Cronbach's alpha was used examine the internal consistency of each measure used within the present study (see Table 1). Race, gender, parental involvement, and living situation (i.e., with parents) were also considered as potential covariates. Within the present analyses, neither gender (i.e., Male $=0$, Female $=$ 1) or living situation (i.e., Living with parents $=1$ and Other $=0$ ) displayed significant differences across emotional DT, emotional distress, depression, stress, or anxiety ( $\mathrm{p}>$ .05). Race, when recoded (i.e., White $=1$ and Other $=0$ ) displayed significant differences in reports of emotional distress between White $(M=15.24$; $S D=12.72)$, versus nonWhite $(\mathrm{M}=11.57 ; \mathrm{SD}=10.60)$ participants $(\mathrm{F}(1,358)=7.91, \mathrm{p}<.01)$. Additionally, a bivariate correlation analysis found that reports of parental involvement were correlated with emotional DT, emotional distress, stress, depression, and anxiety (see Table 1). Thus, race and parental involvement were used as covariates in the analyses conducted.

\section{Bivariate Correlation Analyses}

In order to assess the relationships between each variable of interest, bivariate correlations were conducted (see Table 1). Overparenting was found to be positively associated with emerging adult children's reports of parental involvement. Additionally, the relationship between parent-child relationship satisfaction and perceived parental involvement was found to be significant. The findings further suggest significant 
relationships between overparenting, distress tolerance and emotional distress, as well as stress, depression, and anxiety, independently. However, there was no significant relationship found between overparenting and parent-child relationship satisfaction. Thus, these findings confirm the first hypothesis of this study in that perceived overparenting was negatively correlated with emotional DT. Means, standard deviations, bivariate correlations, and Cronbach's alphas can be found in Table 1.

Initial Second-Order Confirmatory Factor Analysis: DASS-21

Before conducting the mediation analysis, a second-order confirmatory factor analysis was performed in order to ensure that the total score of the DASS-21 could be used as a latent variable for emotional distress. The model consisted of three latent variables comprised of the three subscales within the measure (i.e., depression, anxiety, stress). Each of the variables were indicated by seven items representative of the constructs within the DASS-21.

The fit of this CFA model was assessed via a chi-square difference test, the comparative fit index (CFI), the Tucker-Lewis Index (TLI), and through observing the root mean square of error approximation (RMSEA). It has been suggested that adequate CFI and TLI values fall above .90 , while sufficient RMSEA values are to fall below 05 . The analysis yielded a significant chi-square value $\left(\chi^{2}(1,186)=457.621, \mathrm{p}<.001\right)$, as well as CFI (.91) and TLI (.90). However, the RMSEA value (.06) did not meet the suggested cutoff, which should be considered by those referencing this study. Each of the first-order factor loadings were found to be significant as well $(\mathrm{p}=.001)$, ranging from .45 to .85 (See Figure 1). The first-order factors of depression (.86), anxiety (.94), 
Table 1

Reliability Coefficients, Means, Standard Deviations, and Correlations for Study Measures

\begin{tabular}{|c|c|c|c|c|c|c|c|c|c|c|}
\hline Variable & $\alpha$ & $M(\mathrm{SD})$ & 1 & 2 & 3 & 4 & 5 & 6 & 7 & 8 \\
\hline 1. HPI & .80 & $53.73(13.36)$ & - & $-.25 * *$ & $.14 * *$ & $.13 *$ & $.15 * *$ & $.12 *$ & .09 & $.13^{*}$ \\
\hline 2. DTS & .93 & $35.55(9.57)$ & & - & $-.63 * *$ & $-.58 * *$ & $-.60 * *$ & $-.56^{* *}$ & $.23 * *$ & $.17 * *$ \\
\hline 3. DASS-21 Total & .95 & $13.90(12.17)$ & & & - & $.92 * *$ & $.91 * *$ & $.91 * *$ & $-.33 * *$ & $-.25 * *$ \\
\hline 4. Stress & .86 & $6.28(4.63)$ & & & & - & $.75^{* *}$ & $.77 * *$ & $-.30 * *$ & $-.23 * *$ \\
\hline 5. Depression & .92 & $3.97(4.54)$ & & & & & - & $.73 * *$ & $-.35^{* *}$ & $-.26 * *$ \\
\hline 6. Anxiety & .85 & $3.64(4.13)$ & & & & & & - & $-.24 * *$ & $-.20 * *$ \\
\hline 7. Satisfaction & - & $8.63(2.00)$ & & & & & & & - & $.70 * *$ \\
\hline 8. Involvement & - & $8.43(2.20)$ & & & & & & & & - \\
\hline
\end{tabular}


and stress (.95) significantly loaded onto the latent variable of emotional distress. This provides sufficient rationale for the use of the DASS-21 total score in subsequent analyses.

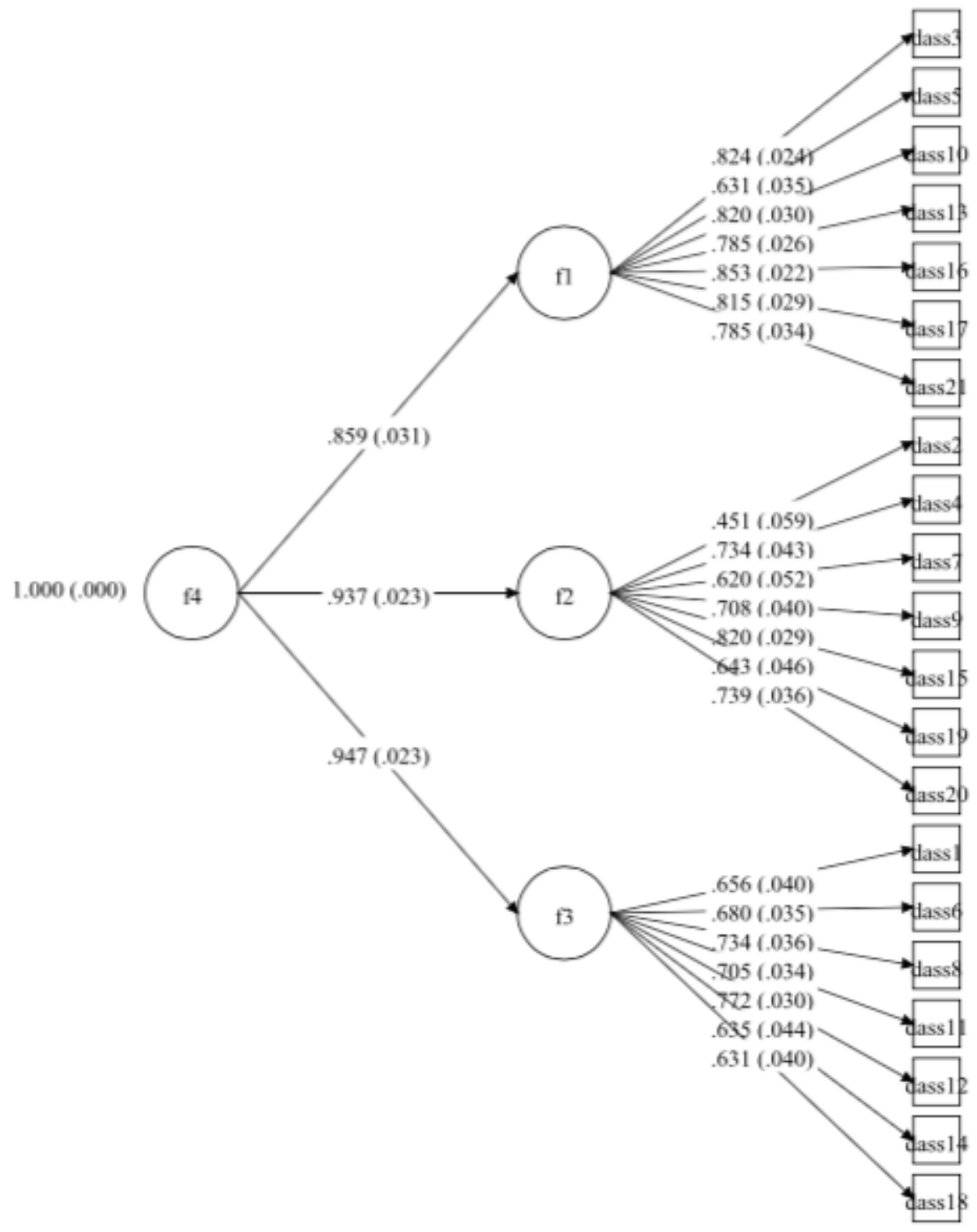

Figure 1. Confirmatory Factor Analysis using Depression, Stress, Anxiety Scales - 21

Note: $\mathrm{f} 4$ = DASS-21 Total Score; $\mathrm{f} 1$ = DASS-21 Depression subscale; $\mathrm{f} 2$ = DASS-21 Anxiety subscale; $\mathrm{f} 3$ = DASS-21 Stress subscale 


\section{Mediation Analyses}

The study implemented a series of regression analyses to determine the predictive nature of overparenting on emotional DT, emotional distress, stress, anxiety, and depression independently, as well as the predictive nature of emotional DT on emotional distress, stress, anxiety and depression. To test the second hypothesis, SPSS PROCESS (Hayes, 2013) was utilized with 10,000 bootstrapped samples in order to estimate $95 \%$ bias-corrected confidence intervals (CI) so that the significance of direct, indirect, and total effects within the mediation models could be assessed. The second hypothesis, which examined the mediating role of emotional DT between overparenting and emotional distress, as well as stress, anxiety, and depression independently, was supported. When accounting for race as a covariate, emerging adults who reported higher levels of overparenting also had lower levels of emotional DT $\left(R^{2}=.11, B=-.20, S E=\right.$ $.04, p<.001)$. Additionally, emotional DT was negatively predicted levels of emotional distress when collapsing the depression, stress, and anxiety subscales of the DASS-21 $\left(R^{2}\right.$ $=.32, B=-.76, S E=.05, p<.001)$. The total effect of overparenting on emotional distress $\left(R^{2}=.11, B=.17, \mathrm{SE}=.05, p<.001\right)$ and indirect effect $[B=.15, \mathrm{SE}=.03, \mathrm{CI}$ $(.08, .22)]$ were significant, although the direct effect $(B=.02, S E=.04, p=.591)$ became nonsignificant once emotional DT was included as a mediator within the model. These results imply that emotional DT fully mediates the relationship between overparenting and emotional distress in emerging adulthood, when accounting for race as a covariate (see Figure 2). 


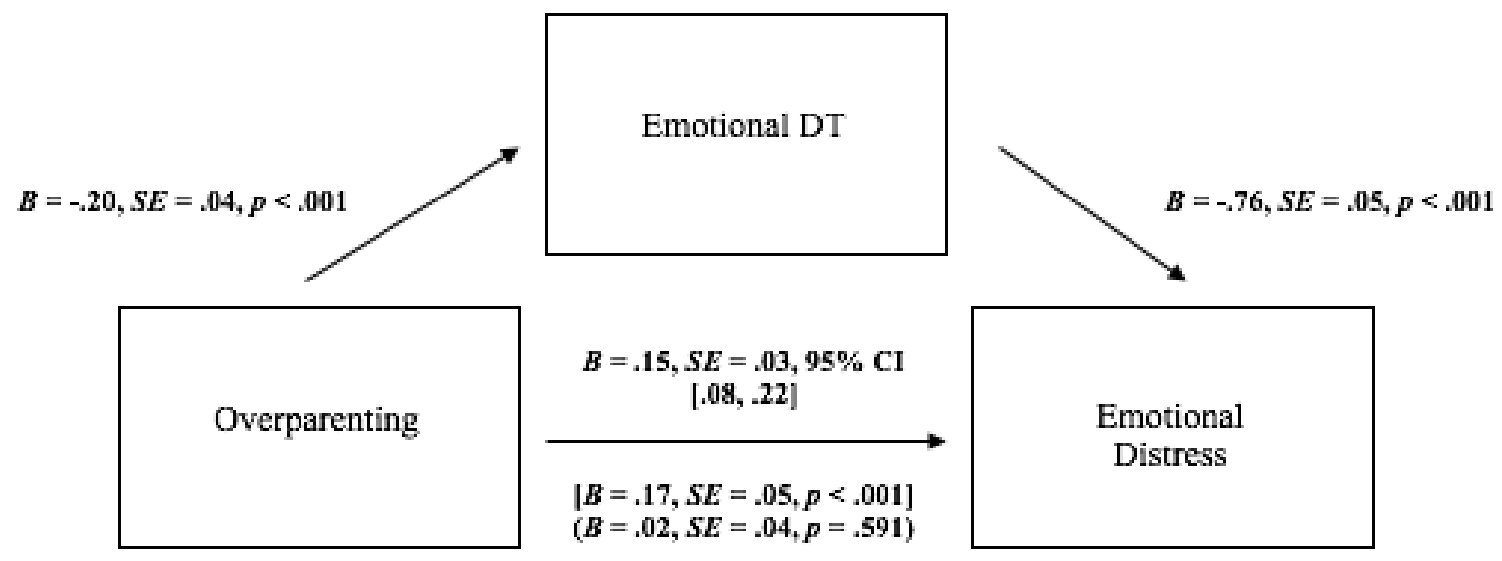

Figure 2. Mediation Analysis with Observed Variable of Emotional Distress

Note: Unstandardized regression coefficients are reported. The statistics in brackets shows the total effect of overparenting on emotional distress; the statistics in parentheses shows the direct effect of overparenting on emotional distress after controlling for the indirect effect of emotional DT (i.e., the mediator). The indirect effect (depicted in center of diagram) was significant based on asymmetric $95 \%$ confidence intervals with 10,000 bootstrapped samples.

Separate mediation models were then run with each of the subscales of the DASS21 (i.e., Depression, Anxiety, Stress) as the dependent variable. Emotional DT was negatively associated with the Depression subscale of the DASS-21 $\left(R^{2}=.27, B=-.26\right.$, $S E=.02, p<.001)$. The total effect of overparenting on depression was found to be significant $\left(R^{2}=.11, B=.06, S E=.02, p<.001\right)$, as well as the indirect effect $(B=.05$, $S E=.01, p<.001)$, while the direct effect $(B=.01, \mathrm{SE}=.01, p=.429)$ became nonsignificant once emotional DT was included as a mediator within the model (see Figure 3). Emotional DT was also negatively associated with the Stress subscale of the DASS-21 $\left(R^{2}=.27, B=-.27, S E=.02, p<.001\right)$. The total effect of overparenting on stress $\left(R^{2}=.10, B=.06, S E=.02, p<.001\right)$ and indirect effect $(B=.05, S E=.01, p<$ $.001)$ were found to be significant as well, while the direct effect $(B=.006, S E=.02, p=$ .668) became nonsignificant when including emotional DT as a mediator (see Figure 4). Lastly, emotional DT was negatively associated with the Anxiety subscale of the DASS- 
$21\left(R^{2}=.22, B=-.23, S E=.02, p<.001\right)$. The total effect of overparenting on anxiety $\left(R^{2}\right.$ $=.07, B=.05, S E=.02, p<.01)$ and indirect effect $(B=.05, S E=.01, p<.001)$ were found to be significant, while the direct effect $(B=.002, S E=.01, p=.877)$ became nonsignificant when including emotional DT as a mediator (see Figure 5). Considering these results, it seems as though emotional DT fully mediates the relationship between overparenting and depression, overparenting and stress, and overparenting and anxiety while accounting for race and parental involvement as covariates.

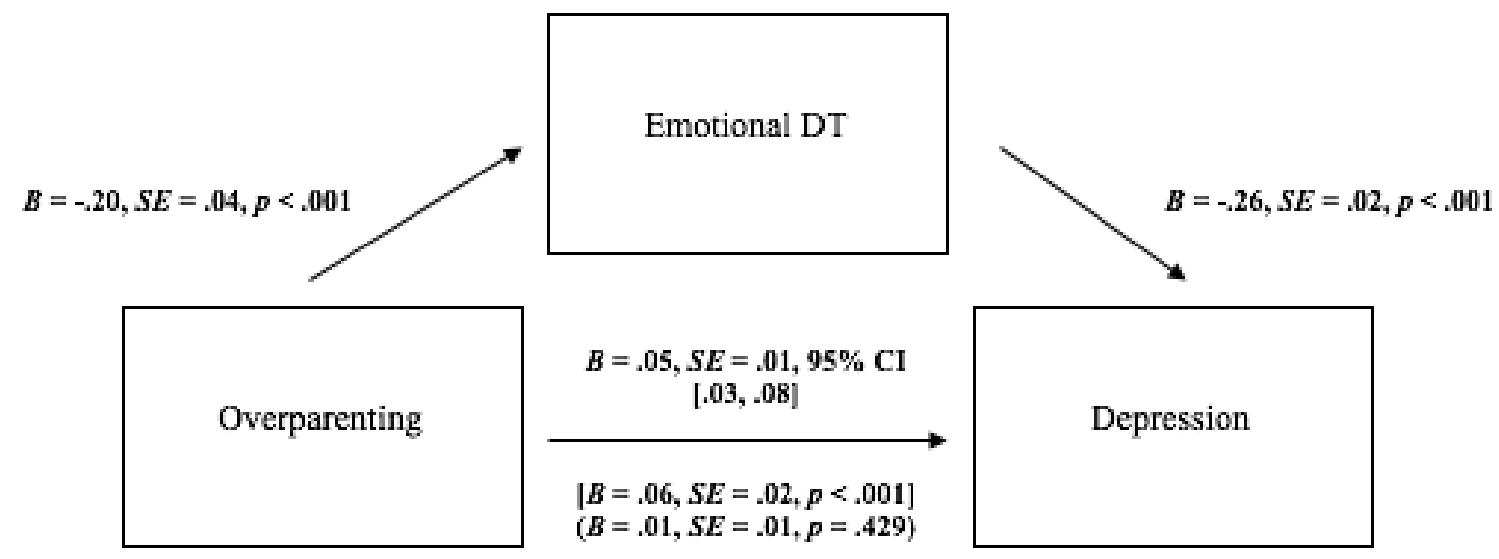

Figure 3. Mediation Analysis Using the Depression Subscale of the Depression, Anxiety, Stress Scales - 21 as a Dependent Variable

Note: Unstandardized regression coefficients are reported. The statistics in brackets shows the total effect of overparenting on depression; the statistics in parentheses shows the direct effect of overparenting on depression after controlling for the indirect effect of emotional DT (i.e., the mediator). The indirect effect (depicted in center of diagram) was significant based on asymmetric $95 \%$ confidence intervals with 10,000 bootstrap samples. 


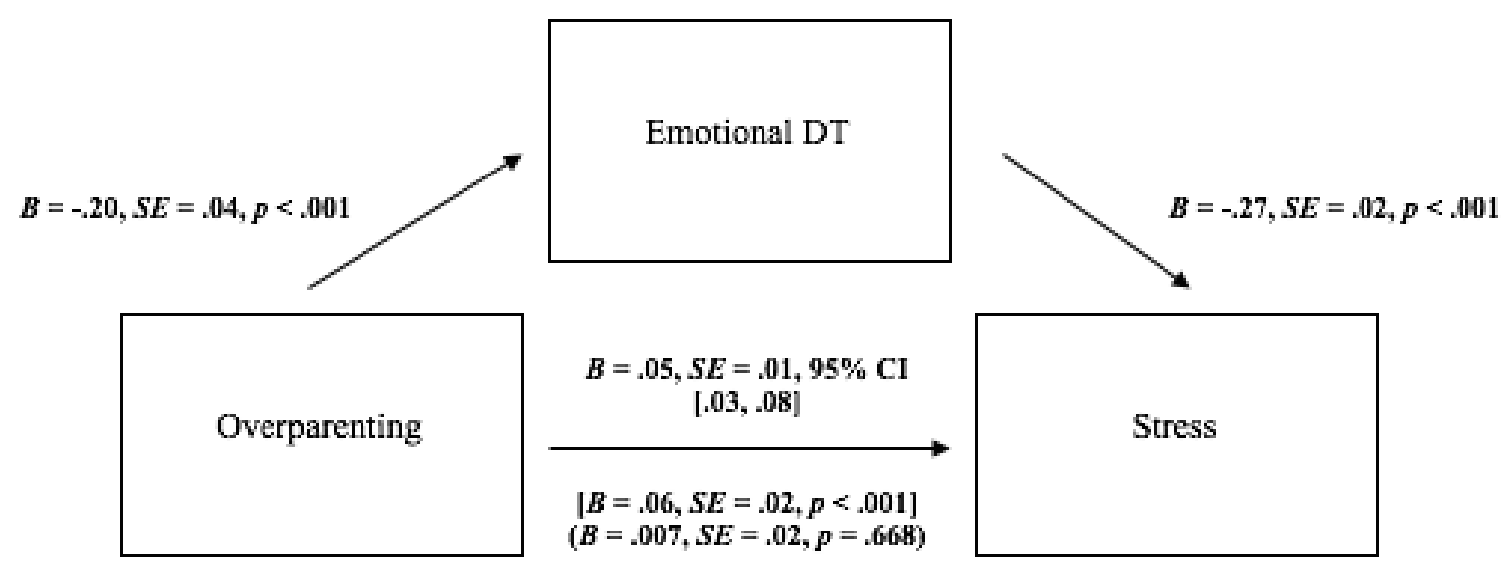

Figure 4. Mediation Analysis Using the Stress Subscale of the Depression, Anxiety, Stress Scales - 21 as a Dependent Variable

Note: Unstandardized regression coefficients are reported. The statistics in brackets shows the total effect of overparenting on stress; the statistics in parentheses shows the direct effect of overparenting on stress after controlling for the indirect effect of emotional DT (i.e., the mediator). The indirect effect (depicted in center of diagram) was significant based on asymmetric $95 \%$ confidence intervals with 10,000 bootstrap samples.

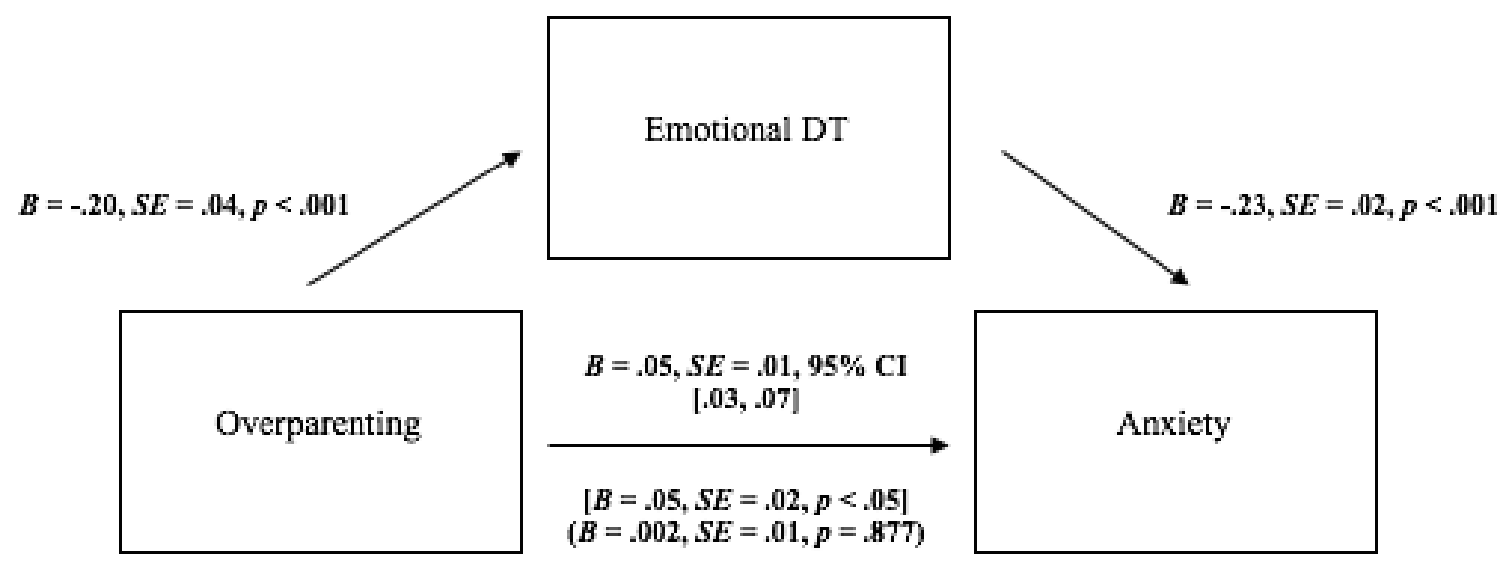

Figure 5. Mediation Analysis Using the Anxiety Subscale of the Depression, Anxiety, Stress Scales - 21 as a Dependent Variable

Note: Unstandardized regression coefficients are reported. The statistics in brackets shows the total effect of overparenting on anxiety; the statistics in parentheses shows the direct effect of overparenting on anxiety after controlling for the indirect effect of emotional DT (i.e., the mediator). The indirect effect (depicted in center of diagram) was significant based on asymmetric $95 \%$ confidence intervals with 10,000 bootstrap samples. 


\section{CHAPTER IV - DISCUSSION}

The current study sought to examine the relationship between overparenting and emotional DT, as well as the mediating role of emotional DT between overparenting and emotional distress in emerging adulthood. Results indicated that overparenting was related to emotional DT and that emotional DT fully mediated the relationship between overparenting and emotional distress, as well as depression, stress, and anxiety independently. These findings are generally consistent with research involving the associations between overparenting and poor mental health outcomes (LeMoyne \& Buchanan, 2011; Padilla-Walker \& Nelson, 2012; Schiffrin et al., 2014; Segrin et al., 2015). This study further indicates that overparenting may be negatively associated with levels of emotional DT in emerging adulthood. Considering previous research that suggests a link between overparenting and dependent personality features (Montgomery, 2010), it could be that low levels of emotional DT are manifested in negative mental health experiences once emerging adults enter an environment where autonomy is expected (i.e., college, work, social) while lacking the necessary preparation. These findings support the continued examination of emerging adults' reliance upon their parents and/or primary caregivers, as well how this impacts the ability to appraise, regulate, and cope with negative emotional situations in an adaptive and autonomous manner. Additionally, this study supports the efforts of parents in assisting the development of age-appropriate behaviors (i.e., financial responsibility, conflict resolution, academic integrity) in their emerging adult children's lives that may lead to success and achievement. 
This study additionally posits that emotional DT may be one mechanism by which overparenting predicts emotional distress, as well as stress, anxiety, and depression, independently. These findings speak to the necessity of emphasizing positive parenting practices regarding the awareness of potentially excessive involvement and support, as well as the negative associated consequences. Emerging adult children may also benefit from becoming aware of their reliance on parental support, which may be considered as maladaptive, and how this may impact their ability to develop resilience and behaviors that are expected in their stage of development. Highlighting the importance of adequate, not excessive, levels of parental involvement for both parents and their emerging adult children may facilitate the development of emotionally and behaviorally adaptive and autonomous lifestyles. Additionally, emerging adults may gain from learning new strategies that assist in coping with emotional distress that they may have not developed at home.

\section{Hypothesis 1}

The first hypothesis concerned the relationship between overparenting and emotional DT in emerging adulthood. As proposed, there was a negative correlation between overparenting and emotional DT, suggesting that high levels of intrusive parenting behaviors may be negatively related to emerging adults' ability to tolerate emotional distress. Researchers have previously found overparenting to be correlated with stress, anxiety, depression (LeMoyne \& Buchanan, 2011; Schiffrin et al., 2014; Segrin et al., 2013), and learned-helplessness (Padilla-Walker \& Nelson, 2012), as well as maladaptive coping mechanisms such as substance abuse (Needham \& Austin, 2010), internalization, and distancing (Segrin et al., 2013) in emerging adulthood. However, 
studies have not yet examined the link between overparenting and emotional DT in emerging adults. The significant relationship between overparenting and emotional DT is consistent with previous research and supports the notion that overparenting behaviors may be negatively correlated with emerging adults' ability to adapt in circumstances during which they perceive negative emotions as overwhelming or potentially intolerable.

Previous studies have also linked lower levels of emotional DT to psychopathological symptoms such as depression and anxiety (Anestis et al., 2007; Keough et al., 2010; Leyro et al., 2010). The study also found that emotional DT was correlated with stress, anxiety, and depression independently, as well as an overall latent variable combining these factors labeled "emotional distress." Therefore, these results further indicate that overparenting may be negatively associated with emerging adults' ability to adaptively handle their experiences of stress, anxiety, and depression.

\section{Hypothesis 2}

Secondly, emotional DT was hypothesized to partially mediate the relationship between overparenting and emotional distress, as well as depression, stress, and anxiety independently in emerging adults. Previously, the mediating role of emotional DT has been examined between various behavioral and emotional constructs such as; posttraumatic stress and substance abuse (Potter et al., 2011), anxiety and eating disorders (Anestis et al., 2007), as well as impulsivity and alcohol abuse (MarshallBerenz et al., 2011). To this point, researchers had not yet examined the mechanism of emotional DT between overparenting and levels of mental health in the emerging adult population. 
The present study found that, when accounting for race and perceived parental involvement as covariates, emotional DT mediated the relationship between overparenting and emotional distress, as well as stress, anxiety, and depression in emerging adults, confirming the second hypothesis. These findings suggest that one mechanism by which overparenting predicts poor mental health in emerging adult college students may be explained by the negative relationship between overparenting and emotional DT, which assesses a person's ability to cope with stress. Tribe and Melluish (2014) stated that psychological and psychiatric research incorporating multicultural considerations seems to be confounded on a global level. That is, studies continue to provide findings in similar demographic groups that contradict each other across the world. A study conducted by Bhui and Dinos (2008) found that understandings and expressions of mental illness vary greatly across cultures and may often be misdiagnosed by clinicians. This study lends reason to believe that this may be the case despite significant cross-cultural differences. While there were significantly different levels of emotional distress reported across race, the results of this study indicated that emotional DT mediates the relationship between overparenting and emotional distress, as well as depression, stress, and anxiety independently, even after accounting for the effects of race as a covariate. Thus, the findings of this study provide insight towards how intrusive parenting may be negatively correlated with emerging adults' ability to adapt to experiences of negative or aversive emotions, which may in turn heighten their experiences of emotional distress.

Interestingly, the bivariate correlation analyses within this study also indicated a positive correlation between parental involvement and level of satisfaction within the 
parent-child relationship, suggesting that high levels involvement were not negatively

perceived by students. Past research has found that emerging adults within the Millennial generation may find overparenting to be normative, as they have been raised in a society where the prevalence in reports of overparenting continue to increase (Fingerman et al., 2012). Findings from Goldscheider, Thornton, and Yang (2001) suggest that emerging adults seemed to expect more parental support than parents originally intended to provide, further proposing that parental involvement may be viewed as less intense during the developmental phase. Locke and colleagues (2016) stated that while high parental involvement has been seen as optimal for well-being and development in childhood, that it may become less beneficial during the transition from adolescence into emerging adulthood. This lends an opportunity to gain a better understanding of what emerging adult children perceive as excessive involvement and for further examination into whether emerging adults who report being over-parented necessarily dislike their respective parents' over-responsiveness.

\section{Limitations}

While the present study was able to provide significant and meaningful results, there were a number of limitations associated within the study. Those referencing this study must consider the retrospective nature of these self-reports of parenting and take into account how this may impact the validity of the findings. Another limitation of this study is the uneven distribution of gender (i.e., majority female), race (i.e., majority White/non-Hispanic), and identified primary caregiver (i.e., majority mother) within the sample. Future studies may gain from over-sampling for male participants to balance these findings across gender. At present, the majority of studies encompassing 
overparenting and mental health correlates have obtained samples made up of female participants, predominantly. Regarding gender, acquiring a more balanced sample may assist in beginning to disseminate the ways in which perceptions of overparenting vary across this construct. Thus, the results of this study may not accurately portray perceived overparenting experiences, emotional DT, and emotional distress outside of emerging adults identifying within this particular demographic. Therefore, individuals interested in the findings of this study must take into account the lack of generalizability of its findings across the emerging adult population in the United States.

\section{Areas for Future Research}

To this point, research that involves mental health correlates of overparenting has much room to expand. An area of opportunity for growth within this literature exists in examining the mediating role of overparenting between emotional DT and emotional distress in emerging adulthood. Perhaps, researchers may benefit from modifying the statistical model within this study to determine whether or not the fit is more desirable when examining overparenting as a mediator within this relationship. Studies have suggested that overparenting may be a reaction to parents' perceptions of their emerging adult children safety being at-risk, although they are in relatively sound environments (Ungar, 2009). Segrin and colleagues (2012) further propose that overparenting may be a reactive effort on parents' behalf to control situational outcomes in school, occupational, and social settings due to perceptions that their emerging adult children are incapable of handling stressful events effectively. Thus, reconstructing the mediation model as such may also assist in identifying overparenting as a response to distress, or perceived 
distress, in emerging adults, rather than a predictive factor, and how this relationship may be associated with psychological health in the emerging adult population.

Studies should also consider why overparenting seems to be related to emotional DT in emerging adulthood. It may be the case that the restriction of age-appropriate autonomous behaviors is negatively correlated with individuals' levels of emotional autonomy. Spokas and Heimberg (2009) found overparenting to be associated with an external locus of control in emerging adults. Overparenting behaviors have also been correlated with dysfunctional emotion-focused coping strategies (Uehara, Sakado, Sato, \& Someya, 1999) and separation anxiety (Soenens, Vansteenkiste, Duriez, \& Goossens, 2006). It is also a possibility that emerging adults who have experienced overparenting have had less opportunity to develop resilience during the time in which their parents have potentially inhibited their autonomous growth. Researchers should consider that overparenting may lead to maladaptive coping behaviors being used in emerging adulthood during times in which emotional states are perceived as negative or overwhelming, rather than utilizing more effective coping strategies.

Another area of opportunity for research may be the effect of overparenting on emerging adult children's affective adaptation, which is characterized by psychological processes that cause affective responses to weaken after repeated exposure to a stimulus (Frederick \& Loewenstein, 1999). Considering that the results of this study indicate overparenting may be negatively related with the extent to which emerging adults can tolerate aversive or negative emotional states, it may further benefit those interested in these constructs to examine how overparenting may be associated with emerging adult children's adaptation to these emotional states. 
Lastly, researchers may benefit from continued measure development to further improve the content validity of current measures to capture and the specific behaviors associated with overparenting. At this time, studies have been able to provide measures of overparenting capable of yielding total scores for overall perceptions of the parenting style. However, measures that disseminate and specify which behaviors more greatly characterize overparenting would lend opportunities to identify which behaviors attribute significant variance within these relationships.

\section{Conclusions}

In sum, the present study found overparenting to be predictive of lower levels of emotional DT in emerging adulthood. Further, this study found emotional DT to mediate the relationship between overparenting and emotional distress in this sample. This study also found that, despite the significant correlations between overparenting and emotional distress, levels of involvement were positively correlated with parent-child relationship satisfaction. Regarding this, researchers must consider the point at which parental involvement becomes excessive, as well as ways in which overparenting may be negatively associated with emerging adults' mental health at an unconscious level. Future studies should also consider addressing the responsive nature of overparenting, as well as other ways this parental style and its behaviors are associated with facets of mental health in the emerging adult population. 
What is your age?

What is your gender?

- Male

- Female

- Other

\section{Please indicate your college status:}

- Freshman

○ Sophomore

○ Junior

- Senior

O Other (please specify)

\section{Please indicate your current living situation}

Off campus (with parents)

O Off campus (without parents; with roommates)

- Off campus (without parents; without roommates)

○ On campus (with roommates)

- On campus (without roommates)

- Other (please indicate):

\section{What is your race?}

○ White/Non-Hispanic

- Black/African-American

- Asian-American

- Native American

- Native Hawaiian/Pacific Islander

O Other 
What is your immediate family's estimated income?
○ $\$ 0-\$ 24,999$
○ $\$ 25,000-\$ 49,999$
- $\$ 50,000-\$ 74,999$
○ $\$ 75,000-\$ 99,999$
○ $\$ 100,000-\$ 124,999$
○ $\$ 125,000-\$ 149,999$
○ $\$ 150,000+$

For the purposes of this study, you will be asked to identify a primary caregiver. This should be the parent, or "primary caregiver" that you consider to currently provide the most support in your life.

○ Mother

○ Father

- Grandfather or other male family member (e.g., uncle)

- Grandmother or other female family member (e.g., aunt)

$\circ \quad$ Other (please describe)

On a scale from 1-10 $(1=$ not involved at all and $10=$ very involved $)$, how involved do you believe your primary caregiver is in your life?
$\circ 1$
$\circ 2$
$\circ 3$
$\circ 4$
$\circ 5$
$\circ 6$
$\circ 7$
○ 8
○ 9
○ 10 
On a scale from 1-10 ( 1 = completely unsatisfied and $10=$ completely satisfied $)$, how satisfied are you in your relationship with your primary caregiver?
○ 1
$\circ 2$
- 3
○ 4
○ 5
○ 6
- 7
○ 8
○ 9
- 10 


\section{APPENDIX B - IRB Approval Letter}

\section{fi \\ (1) THE VNTVERSTT OF \\ WIIII SOUTHERN MISSISSIPPI.}

INSTTTUTTONAL REVIEW BOARD

113 College Drive A5147 | Hattiesburg. MS 39406-000

Phone: 601.266 .5997 | Fax: 601.266.4377 | wuw .usm edu'researchinst itutional review boand

\section{NOTICE OF COMMITTEE ACTION}

The project has been reviewed by The University of Southem Mississippi Institutional Review Board in accordance with Federal Drug Administration regulations (21 CFR 26, 111), Department of Health and Human Services (45 CFR Part 46), and university guidelines to ensure adherence to the following criteria:

- The risks to subjects are minimized.

- The risks to subjects are reasonable in relation to the amlicipated benefits.

- The selection of subjects is equitable.

- Informed consent is adequate and appropriately documented.

- Where appropriate, the research plan makes adequate provisions for moniloring the data collected to ensure the safety of the subjects.

- Where appropriate, there are adequate provisions to protect the privacy of subjects and to maintain the confidentiality of all data.

- Appropriate additional safeguards have been included to protect vulnerable subjects.

- Any unanticipated, serious, or continuing problems encountered regarding risks to subjects must be reported immediately, but not later than 10 days following the event. This should be reported to the IRB Office via the "Adverse Effect Report Form".

- If approved, the maximum period of approval is limited to twelve months.

Projects that exceed this period must submit an application for renewal or continuation.

PROTOCOL NUMBER: 16011502

PROJECT TITLE: Overparenting and Emerging Adults' Mental Health: The Mediating Role of

Distress Tolerance

PROJECT TYPE: New Project

RESEARCHER(S): Christopher Perez

COLLEGEIDIVISION: College of Education and Psychology

DEPARTMENT: Counseling Psychology

FUNDING AGENCY/SPONSOR: N/A

IRB COMMITTEE ACTION: Expedited Review Approval

PERIOD OF APPROVAL: 02/03/2016 to 02/02/2017

Lawrence A. Hosman, Ph.D.

Institutional Review Board 


\section{APPENDIX C ELECTRONIC INFORMED CONSENT}

PURPOSE: The present study seeks to better understand the relationship between parenting and mental health outcomes in emerging adulthood.

DESCRIPTION OF STUDY: The present study will consist of completing several brief questionnaires through a secure web portal via the internet. Completion of the study should take approximately 30 minutes, and participants will receive .5 points of SONA credit. Quality assurance checks will be used in this study to make sure that participants read each question carefully and provide thoughtful answers. Participants who do not pass these checks will not receive credit for completing the study.

BENEFITS: Participants will earn 0.5 research credits for completing this study. Those who do not complete the study or who do not pass the quality assurance checks will not receive research credit. Participants will receive no other direct benefits; however, the information provided may better enable researchers to better understand parenting behaviors and how they may be related to mental health outcomes in emerging adulthood. This study does not involve treatment procedures of any kind, or the potential for medical injury.

RISKS: There are no foreseeable risks associated with the current study, beyond those already present in routine daily life. If any questionnaire material evokes distress during the completion of this study, participants should contact the researcher with concerns immediately.

CONFIDENTIALITY: The online questionnaires are anonymous and the information you provide will be kept strictly confidential. Any potentially identifying information (e.g., IP address) will not be retained with your responses. All data collected from the study will be stored in aggregate form with no identifying information to ensure confidentiality. Data will be stored in a secure location for six (6) years, after which time it will be destroyed.

PARTICIPANT'S ASSURANCE: This project has been reviewed by the Institutional Review Board, which ensures that research projects involving human subjects follow federal regulations. Any questions or concerns about rights as a research participant should be directed to the Chair of the Institutional Review Board, The University of Southern Mississippi, Box 5147, Hattiesburg, MS 39406, (601) 266-6820. Participation in this project is completely voluntary, and participants may withdraw from this study at any time without penalty, prejudice, or loss of benefits. Questions concerning the research should be directed to the primary researcher Christopher Perez (Christopher.m.perez@eagles.usm.edu) or the research supervisor, Dr. Bonnie Nicholson (bonnie.nicholson@usm.edu).

If you experience distress as a result of your participation in this study, please notify the primary researcher Christopher Perez (christopher.m.perez@eagles.usm.edu) or the 
research supervisor, Dr. Bonnie Nicholson (bonnie.nicholson@usm.edu). A list of available agencies that may able to provide services for you are provided below:

Community Counseling and Assessment Clinic (601) 266-4601

Student Counseling Services (601) 266-4829

Pine Belt Mental Healthcare (601) 544-4641

Forrest General Psychology Service Incorporated (601) 268-3159

By selecting "Yes" below, consent is hereby given to participate in this study.

I have read the informed consent agreement associated with this study, and hereby provide informed consent of my participation.

○ Yes

○ No 


\section{REFERENCES}

Ali, B., Ryan, J.S., Beck, K.H., \& Daughters, S.B. (2013). Trait aggression and problematic alcohol use among college students: the moderating effect of distress tolerance. Alcoholism: Clinical and Experimental Research, 37(12), 2138-2144. doi:10.1111/acer.12198

Anestis, M.D., Bagge, C.L., Tull, M.T., \& Joiner, T.E. (2011). Clarifying the role of emotion dysregulation in the interpersonal-psychological theory of suicidal behavior in an undergraduate sample. Journal of Psychiatric Research, 45, 603611.

Anestis, M.D., Lavender, J.M., Marshall-Berenz, E.C., Gratz, K.L., Tull, M.T., \& Joiner, T.E. (2012). Evaluating distress tolerance measures: interrelations and associations with impulsive behaviors. Cognitive Therapy and Research, 36(6), 593-602.

Anestis, M.D., Selby, E.A., Fink, E.L., \& Joiner, T.E. (2007). The multifaceted role of distress tolerance in dysregulated eating behaviors. International Journal of Eating Disorders, 40(8), 718-726.

Arnett, J.J. (2007). Emerging adulthood: what is it, and what is it good for? Child Development Perspectives, 1(2), 68-73.

Bayer, J., Sanson, A., \& Hemphill, S. (2006). Parent influences on early childhood externalizing difficulties. Journal of Applied Development Psychology, 27, 542559.

Bebes, A., Samarova, V., Shilo, G., \& Diamond, G.M. (2015). Parental acceptance, parental psychological control, and psychological symptoms among sexual 
minority adolescents. Journal of Child and Family Studies, 24(4), 882-890. doi:10.1007/s10826-01309897-9

Beck, A. T., \& Steer, R. A. (1990). Manual for the Beck Anxiety Inventory. San Antonio, TX: Psychological Corporation.

Beck, A. T., Steer, R. A., \& Brown, G. K. (1996). Manual for the revised Beck Depression Inventory-II. San Antonio, TX: Psychological Corporation.

Bhui, K. \& Dinos, S. (2008). Essential considerations for outcome measurement. Disease Management and Health Outcomes, 16(6), 411-419.

Cohen, S., Kamarck, T., \& Mermelstein, R. (1983). A global measure of perceived stress. Journal of Health and Social Behavior, 24(1), 385-396.

Cusimano, A.M., \& Riggs, S.A. (2013). Perceptions of interparental conflict, romantic attachment, and psychological distress in college students. Journal of Couple and Family Psychology: Research and Practice, 2(3), 45-59. doi:10.1037/a0031657

Daughters, S.B., Gorka, S.M., Rutherford, J.V.H., \& Mayes, L.C. (2014). Maternal and adolescent distress tolerance: the moderating role of gender. Emotion, 14(2). 416424. doi:10.1037/a0034991

Ehrlich, K.B., Cassidy, J., Gorka, S.M., Lejuez, C.W., \& Daughters, S.B. (2013). Adolescent friendships in the context of dual risk: the roles of low adolescent distress tolerance and harsh parental response to adolescent distress. Journal of Emotion, 13(5). 843-851. doi:10.1037/a0032587

Eisenberg, N., Cumberland, A., \& Spinrad, T.L. (1998). Parental socialization of emotion. Psychological Inquiry, 9, 241-273. doi:10.1207/s15327965pli0904_1 
Ellis, A.J., Fischer, K.M., \& Beevers, C.G. (2010). Is dyptheria about being red and blue? Potentation of anger and reduced distress tolerance among dysphoric individuals. Cognition \& Emotion, 24, 596-608.

Ellis, A.J., Vanderlind, W.M., \& Beevers, C.G. (2013). Enhanced anger reactivity and reduced distress tolerance in major depressive disorder. Cognitive Therapy and Research, 27(3), 498-509. doi:10.1007/s10609-012-9494-z

Field, A. P. (2013). Discovering statistics using IBM SPSS statistics: And sex and drugs and rock ' $n$ ' roll (4th ed.). Los Angeles, CA: Sage.

Fingerman, K.L., Cheng, Y., Wesselmann, E.D., Zarit, S., Furstenburg, F., \& Birditt, K.S. (2012). Helicopter parents and landing pad kids: intense parental support of grown children. Journal of Marriage and Family, 74, 880-896.

DOI:10.1111/j.1741-3737.2012.00987.x

Frederick, S., \& Loewenstein, G. (1999). Hedonic adaptation. In E. Diener, N. Schwartz, \& D. Kahneman (Ed.), Hedonic psychology: Scientific approaches to enjoyment, suffering, and well-being (pp. 302-329). New York, NY: Russell Sage Foundation Press.

Gar, N.S., \& Hudson, J.L. (2008). An examination of the interactions between mothers and children with anxiety disorders. Behaviour Research and Therapy, 46(12), $1266-1274$

Gaher, R.M., Hofman, N.L., Simons, J.S., \& Hunsaker, R. (2013). Emotion regulation deficits as mediators between trauma exposure and borderline symptoms. Cognitive Therapy Research, 37, 466-473. doi:10.1007/s10608-012-9515-y. 
Goldscheider, F.K., Thornton, A., \& Yang, L.S. (2001). Helping out the kids:

Expectations about parental support in young adulthood. Journal of Marriage and Family, 63, 727-740. doi:10.1111/j.1741-3737.2001.00727.x

Hauser Kunz, J., \& Grych, J.H. (2013) Parental psychological control and autonomy granting: distinctions and associations with child and family functioning. Parenting Science and Practice, 13(1), 77-94. doi:10.1080/15295192.2012.709147

Hawkins, K.A., Macatee, R.J., Guthrie, W., \& Cougle, J.R. (2013). Concurrent and prospective relations between distress tolerance, life stressors, and anger. Cognitive Therapy and Research, 37(3), 434-445.

Hayes, A.F. (2013). Introduction to mediation, moderation, and conditional process analysis: a regression-based approach. Guilford Press.

Huang, J.L., Curran, P.G., Keeney, J., Poposki, E.M., \& DeShon, R.P. (2012). Detecting and deterring insufficient effort responding to surveys. Journal of Business and Psychology, 27(1), 99-114.

Huang, K., Szabo, M., \& Han, J. (2009). The relationship of low distress tolerance to excessive worrying and cognitive avoidance. Behaviour Change, 26, 223-234.

Kaiser, A.J., Milich, R., Lynam, D.R., \& Charnigo, R.J. (2012). Negative urgency, distress tolerance, and substance abuse among college students. Addictive Behaviors, 37. 1075-1083. doi:10.1016/j.addbeh.2012.04.017

Keough, M.E., Riccardi, C.J., Timpano, K.R., Mitchell, M.A., \& Schmidt, N.B. (2010). Anxiety symptomology: The association with distress tolerance and anxiety sensitivity. Behavior Therapy, 41, 567-574. doi:10.1016/j.beth.2010.04.002 
Kraemer, K.M., Luberto, C.M., \& McLeish, A.C., (2012). The moderating role of distress tolerance in the association between anxiety sensitivity physical concerns and panic and PTSD-related re-experiencing symptoms. Anxiety, Stress, \& Coping, 26, (3), 330-342. http://dx.doi.org/10.1080/10615806.2012.693604

Lejuez, C.W., Banducci, A.N., \& Long, K. (2013). Commentary on the distress tolerance special issue. Journal of Cognitive Therapy Research, 37, 510-513. doi:10.1007/s10608-013-9537-2

LeMoyne, T., \& Buchanan, T. (2011). Does "hovering" matter? Helicopter parenting and its effect on well-being. Sociological Spectrum, 31(1), 399-418. doi:10.1080/02732173.2011.574038

Leyro, T.M., Zvolensky, M.J., \& Bernstein, A. (2010). Distress tolerance and psychopathological symptoms and disorders: a review of the empirical literature among adults. Psychological Bulletin, (136)4, 576-600. doi:10.1037/a0019712

Leyro, T.M., Bernstein, A., Vujanovic, A.A., McLeish, A.C., \& Zvolensky, M.J. (2011) Distress Tolerance Scale: A confirmatory factor analysis among daily cigarette smokers. Journal of Psychopathological Behavior Assessment, 33, 47-57. DOI $10.1007 / \mathrm{s} 10862-010-9197-2$

Li, X., Li, D., \& Newman, J. (2013). Parental behavioral and psychological control and problematic internet use among Chinese adolescents: The mediating role of selfcontrol. Cyberpsychology, Behavior, and Social Networking, 16(6), 442-447. doi:10.1089/cyber.2012.0293

Locke, J.Y., Campbell, M.A., \& Kavanaugh, D. (2012). Can a parent do too much for their child? An examination by parenting professionals of the concept of 
overparenting. Australian Journal of Guidance and Counseling, 22(2), 249-265. doi:10.1017/jgc.2012.29

Locke, J.Y., Kavanaugh, D.J., \& Campbell, M.A. (2016). Overparenting and homework: the student's task, but everyone's responsibility. Journal of Psychologists and Counsellors in Schools, 26(1), 1-15. doi:10.1017/jgc.2015.29

Lovibond, S.H., \& Lovibond, P.F. (1995). Depression Anxiety Stress scales. Psyctests, doi:10.1037/t01004-000

Manzeske, D.P., \& Stright, A. (2009) Parenting styles and emotion regulation: the role of behavioral and psychological control during young adulthood. Journal of Adult Development, 16(4), 223-229. doi:10.1007/s10804-009-9068-9

Marshall-Berenz, E.C., Vujanovic, A.A., \& MacPherson, L. (2011). Impulsivity and alcohol use coping motives in a trauma-exposed sample: The mediating role of distress tolerance. Personality and Individual Differences, 50, 588-592. doi:10.1016/j.paid.2010.11.033

McDowell, D.J., Kim, M., O’Neil, R., \& Parke, R.D. (2002). Children's emotional regulation and social competence in middle childhood: The role of maternal and paternal interactive style. Marriage and Family Review, 34, 345-365.

Moilanen, K.L. (2007). The adolescent self-regulatory inventory: The development and validation of a questionnaire of short-item and long-term self-regulation. Journal of Youth and Adolescence, 36, 835-848.

Montgomery, N. (2010). The negative impact of helicopter parenting on personality.

Poster presented at the annual meeting of the Association of Psychological Science, Boston, MA. 
Morris, A.S., Silk, J.S., Steinberg, L., Myers, S.S., \& Robinson, L.R. (2007). The role of family context in the development of emotion regulation. Social Development, 16, 361-388. doi:10.1111/j.1467-9507.2007.00389.x

Needham, B.L., \& Austin, E.L. (2010) Sexual orientation, parental support, and health during the transition to young adulthood. Journal of Youth Adolescence, 39(1), 1189-1198. doi:10.1007/s10964-010-9533-6

Odenweller, K.G., Booth-Butterfield, M., \& Weber, K. (2014). Investigating helicopter parenting, family environments, and relational outcomes for Millennials. Communication Studies, 65(4), 407-425. doi:10.1080/10510974.2013.811434

Osman, A., Wong, J. L., Bagge, C. L., Freedenthal, S., Gutierrez, P. M., \& Lozano, G. (2012). The Depression Anxiety Stress Scales-21 (DASS-21): Further examination of dimensions, scale reliability, and correlates. Journal of Clinical Psychology, 68(12), 1322-1338.

Padilla Walker, L.M., \& Nelson, L.J. (2012) Black hawk down? Establishing helicopter parenting as a distinct construct from other forms of parental control during emerging adulthood. Journal of Adolescence, 35(5), 1177-1190. doi:10.1016/j.adolescence.2012.03.007

Potter, C.M., Vujanovic, A.A., Marshall-Berenz, E.C., Bernstein, A., \& Bonn-Miller, M.O. (2011). Posttraumatic stress and marijuana use coping motives: The mediating role of distress tolerance. Journal of Anxiety Disorders, 25, 437-443. doi:10.1016/j.janxdis.2010.11.007

Rhoades, G.K., \& Wood, L.F. (2014). Family conflict and college-student social adjustment: the mediating role of emotional distress about the family. Journal of 
Couple and Family Psychology: Research and Practice, 3(3).

doi:10.1037/cfp0000024

Schaefer, E. S. (1965). Children's reports of parental behavior: An inventory. Child development, 1(1), 413-424.

Schiffrin, H.H., Liss, M., Miles-McLean, H., Geary, K.A., Erchull, M.J., \& Tashner, T. (2014). Helping or hovering? The effects of helicopter parenting on college students' well-being. Journal of Child and Family Studies, 23(1), 548-557. doi:10.1007/a10826-013-9716-3

Segrin, C., Woszidlo, A., Givertz, M., Bauer, A., \& Murphy, M. (2012). The association between overparenting, parent-child communication, and entitlement and adaptive traits in adult children. Family Relations: An Interdisciplinary Journal of Applied Family Studies, 61(2), 237-252. doi:10.1111/j.1741-3729.2011.00689.x

Segrin, C., Woszidlo, A., Givertz, M., \& Montgomery, N. (2013). Parent and child traits associated with overparenting. Journal of Social and Clinical Psychology, 32(6), 569-595.

Segrin, C., Givertz, M., Swaitowski, P., \& Montgomerey, N, (2015). Overparenting is associated with child problems and a critical family environment. Journal of Child \& Family Studies, 24, 470-479. doi:10.1007/s1086-013-9858-3

Sideridis, G.D., \& Kafetsios, K. (2008). Perceived parental bonding, fear of failure and stress during class presentations. International Journal of Behavioural Development, 32, 119-130. DOI 10.1177/0165025407087210 
Simons, J.S., \& Gaher, R.M. (2005). The Distress Tolerance Scale: development and validation of a self-report measure. Motivation \& Emotion, 29(2), 83-102. doi:10.1007/s11031-00507955-3

Soenens, B., Vansteenkiste, M., Duriez, B., \& Goossens, L. (2006). In search of sources of psychologically controlling parenting: the role of separation anxiety and parental maladaptive perfectionism. Journal of Research on Adolescence, 16, 539-559.

Soenens, B., Vansteenkiste, M., \& Luyten, P. (2010). Toward a domain-specific approach to the study of parental psychological control: distinguishing between dependency-oriented and achievement-oriented psychological control. Journal of Personality, 78(1), 218-256. DOI:10.1111/j.1467-6494.2009.00614.x

Spokas, M., \& Heimberg, R.G. (2009). Overprotective parenting, social anxiety, and external locus of control: Cross-sectional and longitudinal relationships. Cognitive Therapy and Research, 33(6), 543-551.

Strayer, J., \& Roberts, W. (2004). Children's anger, emotional expressiveness, and empathy: Relations with parents' empathy, emotional expressiveness, and parenting practices. Social Development, 13, 229-254.

Tribe, R., \& Melluish, S. (2014). Globalization, culture, and mental health. International Review of Psychiatry, 26(5), 535-537. DOI: 10.3109/09540261.2014.955086

Tucker, C.J., Holt, M., \& Wiesen-Martin, D., (2013). Inter-parental conflict and sibling warmth during adolescence: associations with female depression in emerging adulthood. Psychological Reports: Relationships \& Communications, 112(1), 243-251. doi:10.2466/21.10.PR0.112.1.243-251 
Uehara, T., Sakado, K., Sato, T., \& Someya, T. (1999). Do perceived parenting styles influence stress coping in patients with major depressive disorders? Stress Medicine, 15, 197-200. DOI 10.1002/(SICI)1099-1700(199907)15:3<197::AIDSM1815>3.0.CO;2-W

Ungar, M. (2009). Overprotective parenting: Helping parents provide the right amount of risk and responsibility. The American Journal of Family Therapy, 37, 258-271. doi:10.1080/01926180802534247

Winner, N.A. (2016). Parenting practices and young adults' emotional distress: the moderating roles of family structure and race (Master's Thesis). Retrieved from The University of Southern Mississippi, Aquila Digital Community. http://aquila.usm.edu/masters_theses/165/

Zvolensky, M.J., \& Hogan, J. (2013). Distress tolerance and its role in psychopathology. Cognitive Therapy Research, 37, 419-420. doi:10.1007/s10608-013-9533-4 